\title{
NOVEDADES EN GALIANTHE (RUBIACEAE)
}

\author{
por ELSA L. CABRAL*
}

\section{Summary}

Ten new species of Galianthe are described and illustrated: G. bisepala (Argentina), G. linearifolia (Argentina and Paraguay), G. aurelii, G. parvula and G. canindeyuensis (Paraguay), G. pseudopeciolata (Paraguay and Brasil), G. elegans, G. gertii, G. latistipula and G. grandifolia (Brasil).

Durante el curso de la revisión del género Galianthe se han hallado novedades para la flora argentina, paraguaya y brasileña.

En este trabajo se dan a conocer 10 especies nuevas que se agregan a las 20 entidades citadas para el género (Cabral, 1991).

Para la Argentina se describen: G. bisepala coleccionada hasta el momento sólo en la provincia de Salta y $G$. linearifolia hallada en la provincia de Misiones, la cual también vive en Paraguay en el departamento Alto Paraná.

G. aurelii, G. parvula y G. canindeyuensis fueron halladas hasta el presente sólo en Paraguay,mientras que G. pseudopeciolata se la coleccionó también en Brasil (Mato Grosso do Sul, São Paulo y Paraná). A la flora brasileña se incorporaron además: G. elegans, G. gertii (Paraná), G. latistipula (Sta. Catarina, Rio Grande do Sul) y G. grandifolia (Mato Grosso, Distrito Federal, Goiás, Minas Gerais).

\section{Galianthe aurelii Cabral nov. sp.}

Fig. 1

Suffrutex ramosissimus, $30-80 \mathrm{~cm}$ altus. Caules quadrangulares, glabres. Foliae lineari-lanceolatae vel lanceolatae, glabrae, basi decurrente, pseudopeciolata 12-60

* Facultad de Ciencias Exactas y Naturales y Agrimensura (UNNE). IBONE, Casilla de Correo 209, Corrientes, Argentina. 
x $1.8 \mathrm{~mm}$. Vagina stipulari puberula vel glabri, laciniis 4-6 longis, glabribus. Thyrsi in ramis principalibus et lateralibus; corolla externe micropapillata. Flos brevistyli, stylo bifurcato in tertie superiore, ramis stigmaticis linearibus ex bifurcatione papilis pluricelularibus. Flos longistyli, ramis stigmaticis spatulatis, papilis pluricelularibus. Capsula glabra, turbinata. Semina subcylindrica, ventre plano sulcato circum strophiolo.

Typus. PARAGUAY. Guairá, Colonia Independencia, Cerro Pelado, I. 1967, A. Schinini 2111 (Holotypus: CTES; Isotypi: G, LIL, MO).

Sufrútice muy ramificado de $30-80 \mathrm{~cm}$ altura, tallos tetrágonos, glabros, 1-2 mm lat., sin xilopodio. Hojas linear-lanceoladas a lanceoladas, glabras 12-60 x 1-8 mm, ápice agudo a muy atenuado, base decurrente formando pseudopecíolo, bordes recurvos, 3-5 pares de venas secundarias alternas o subopuestas con ángulo de divergencia $5^{\circ}-10^{\circ}$, hundidas en el haz, prominentes en el envés, venación terciaria inconspicua. Vaina estipular, 1,25-2 mm long., pubérula a glabra con rafidios dispersos, 4-6 lacinias filiformes, 2-6 mm long., con pelos cortos y densos en la base. Tirsos en ramas principales. Cáliz con 4 lóbulos triangulares, agudos, 0,751,25 mm long., hipantio I-1,25 mm long., glabro. Corola blanca, superficie externa micropapilosa, papilas más largas forman una cresta media en el dorso de los lóbulos; disco entero papiloso. Flor brevistila: corola, 3-5 mm long., lóbulos más cortos que el tubo, superficie interna con dos anillos de pelos moniliformes, uno inferior de pelos delgados, dispersos sobre el tubo y otro de pelos densos sobre la mitad inferior de los lóbulos; filamentos estaminales de 1-1,50 mm y anteras de 1-1,25 mm; estilo 2-2,50 $\mathrm{mm}$, bifurcado en el tercio superior, ramas estigmáticas lineares con papilas pluricelulares. Flor longistila: corola 3,25-4 mm long., lóbulos iguales o más largos que el tubo, superficie interna con un anillo de pelos moniliformes delgados sobre la mitad del tubo y otro de pelos más gruesos sobre la mitad de los lóbulos; filamentos estaminales muy breves y

Fig. 1.- Galianthe aurelii. A, rama, B, vaina estipular; C, flor brevistila; D-E, cáliz y corola de la flor brevistila (holotipo); F, flor longistila; G-H, cáliz y corola de la flor longistila (T. Rojas 4885); I, fruto; J-K, scmilla cara dorsaí y ventral. 
Novedades en Galianthe

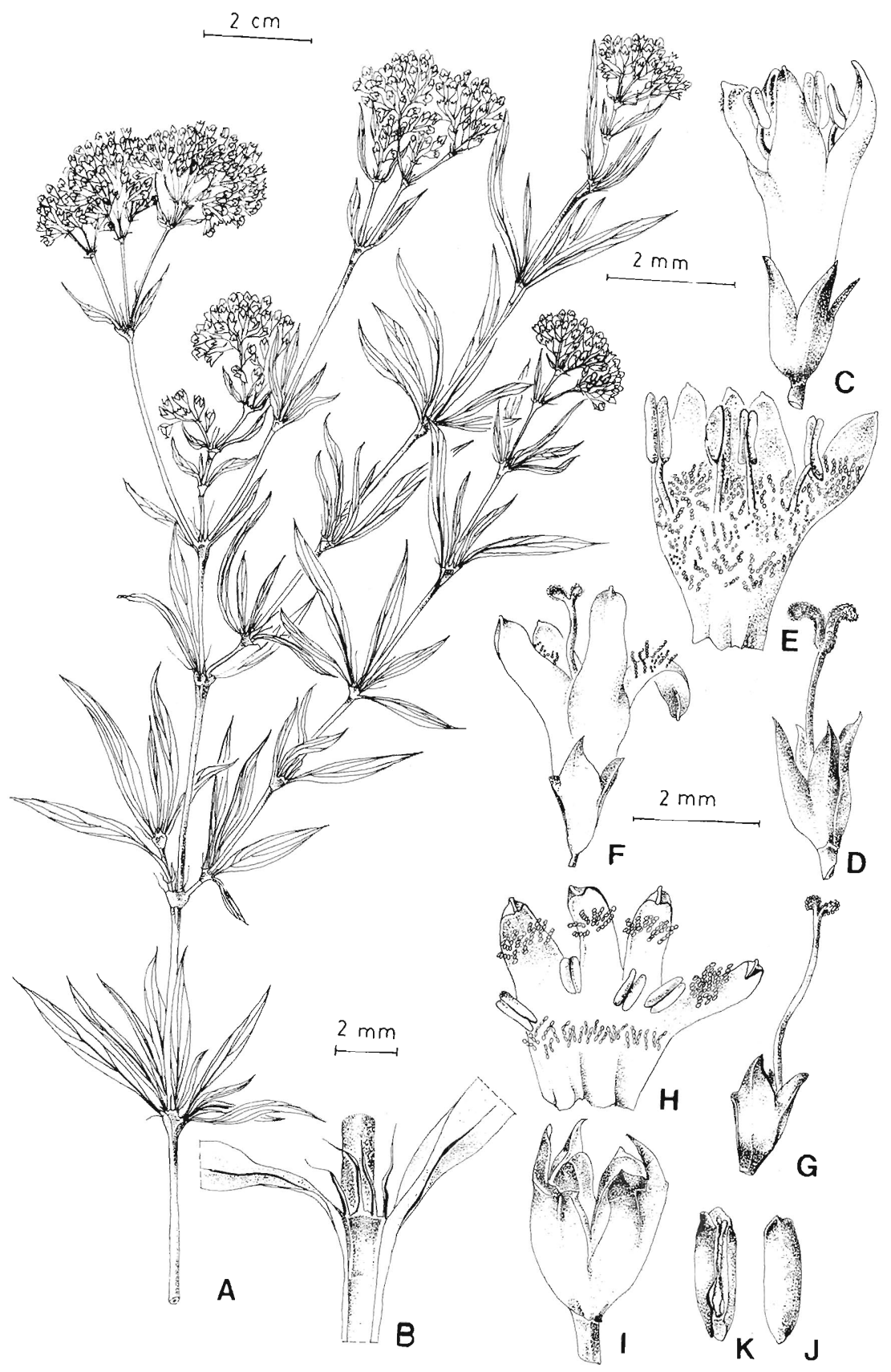


anteras de 0,75-1 $\mathrm{mm}$; estilo 3-3,50 $\mathrm{mm}$, con papilas dispersas, ramas estigmáticas espatuladas con densas papilas pluricelulares. Fruto glabro, turbinado, 2,50-3 mm long., con rafidios dispersos longitudinalmente. Semilla subcilíndrica, foveolada 2-2,50 mm long., plano-convexa, con surco alrededor del estrofíolo.

Distribución geográfica. Vive en Paraguay en los departamentos Cordillera, Guairá y Amambay, preferentemente en cerros, entre rocas desnudas.

Paratipos. PARAGUAY. Cordillera, Piribebuy, Ygay-mi, 27.IV.1983, Soria 920 (CTES, FCQ). Guairá, Cerro de Villarrica, IV.1924, Rojas, 4885 (SI); Cerro Pelado, IV.1876, Balansa 1748 a (P); ibid., I.1905, Hassler 8784 (G); Colonia Independencia, I.1967, Schinini 1444 (CTES, SI). Amambay, cerca del Parque Nacional Cerro Corá, 9.II.1982, Fernández Casas 6133 (G); Cerro Sarambí a 12 km del Parque Nacional Cerro Corá, 6.V.1989, Bacigalupo et al. 1151 (CTES, SI).

Obs. G. aurelii se aproxima a Galianthe paraguariensis (Chodat et Hassler) Cabral, por su cuerpo vegetativo muy ramificado, con inflorescencias en las ramas principales, pero esta especie tiene hojas, vaina estipular e hipantio pubescente; el disco bipartido, piloso; además la flor brevistila presenta el estilo dividido hasta la mitad y las ramas estigmáticas con papilas unicelulares, mientras que el estilo de la flor longistila tiene las ramas estigmáticas con papilas densas y largas en los extremos.

Dedico esta especie a Aurelio Schinini, quien a través de sus colecciones ha contribuido permanentemente con ejemplares de Galianthe, y en esta oportunidad ha colectado el ejemplar elegido como tipo.

\section{Galianthe bisepala Cabral nov. sp.}

Fig. 2

Suffrutex ramosissimus 0,4-1 $\mathrm{m}$ alt. Caules quadrangulares, puberuli vel glabrescentes, internodiis $0,5-4 \mathrm{~cm}$ long. Foliae pseudofasciculatae, sessilae, lineares vel linear-lanceolatae 5-40 $\times 0,5-3,5 \mathrm{~mm}$, utrinque glabrescentes vel scabridi; vagina stipulari puberula a pubescente, laciniis 4-6 glabriis, 1,25-3 mm long. Thyrsi in ramis principalibus et lateralibus; corolla externe pubescens, calyce lobulis 2 (4), 
dentibus interlobularis, hypanthio pubescente 1,25-2 $\mathrm{mm}$ long.; disco integer pubescente. Flos brevistyli: corolla 3-3,75 mm long., tubo intus medium annularipilis moniliformis. Flos longistyli: corolla 3,25-3,50 mm long., intus 2 annulari-pilosis moniliformis: I lobos, I tubo. Capsula pilosa, 3-5 mm long.; semina complanata 2,75$3 \mathrm{~mm}$.

Typus. ARGENTINA. Salta, La Viña. Quebrada de las Conchas, entre la Salamanca y el Hongo, Ruta 68 km 77-78, alt. $1.300 \mathrm{~m} \mathrm{s.m.,} \mathrm{10.III.1990,} \mathrm{L.} \mathrm{Novara}$ y S. Bruno 9630 (Holotypus: MCNS; Isotypi: AAU, B, CORD, CTES, G, M, MAAU).

Sufrútice muy ramificado desde la base de 0,4-1 $\mathrm{m}$ de alt., con ramas laterales desarrolladas que rematan en inflorescencias; tallos tetrágonos, pubérulos a glabrescentes, entrenudos $0,5-4 \mathrm{~cm}$ long. Hojas linear o linear-lanceoladas, sésiles, 5-40 x 0,5-3,5 mm, bordes revolutos, ápice agudo, glabrescentes o haz glabro y envés pubérulo, a veces escábridas en ambas caras, vena principal surcada en el haz y prominente en el envés, venas secundarias obsoletas o inconspicuas. Vaina estipular pubérula o pubescente, 1-2 mm long., con 4-6 lacinias, filiformes, glabras, 1,25-3 mm long., con glándulas apicales. Tirsos paucifloros terminales. Cáliz con predominio de 2 sépalos, en la misma inflorescencia, cuando presentan 4 sépalos, 2 de ellos son mayores, con dientes intercalares, hipantio turbinado, pubescente, 1,25-2 mm long. Corola blanca, externamente pubescente, disco entero pubescente. Flor brevistila: corola 3-3,75 mm long., lóbulos más cortos que el tubo corolino; superficie interna con pelos moniliformes desde la mitad del tubo hasta la base de los lóbulos; filamentos estaminales $1,25-1,50 \mathrm{~mm}$ y anteras de $0,75-1,2 \mathrm{~mm}$; estilo 22,25 mm bífido desde la mitad, ramas estigmáticas lineares agudas. Flor longistila: corola 3,25-3,50 mm long., lóbulos más largos que el tubo corolino; superficie interna con 2 anillos de pelos moniliformes, uno de pelos delgados sobre la mitad del tubo y otro denso, de pelos gruesos sobre la mitad de los lóbulos; filamentos estaminales muy breves y anteras 0,75-1 mm, estilo 2,5-4 mm, dividido en su extremo, ramas estigmáticas cortas, recurvadas con papilas densas. Fruto subelipsoide, 3-5 mm long., piloso, con rafidios dispersos; semillas complanadas, 2,75-3 mm long., con cara dorsal convexa y cara ventral cóncava, ligeramente alada en un extremo. 
Distribución geográfica. G. bisepala vive en lugares áridos, ladera de cerros, borde de camino, ca. $1200 \mathrm{~m} \mathrm{s.m.} \mathrm{Sólo} \mathrm{ha} \mathrm{sido} \mathrm{coleccionada} \mathrm{en}$ la Argentina en la provincia de Salta, en un área muy reducida ubicada en los departamentos de La Viña y Guachipas.

Paratipos. ARGENTINA. Salta, Guachipas, Alemanía, 14.IV.1963, Correa 521 (MCNS); Alemanía, Boca de la Quebrada, 19.III.1927, Schreiter 5424 (CTES, LIL). La Viña, Quebrada de las Conchas, 14.III.1958, Cabrera et al. 13062 (SI); próximo al Dique Cabra Corral, 17.VI.1982, Novara 2777 (MCNS, SI).

Obs. Galianthe bisepala es afín a Galianthe krausei (Suessenguth) Cabral, especie paraguaya encontrada sólo en el departamento Cordillera. Ambas presentan un cuerpo vegetativo sufruticoso muy ramificado y hojas angostas, pero se pueden diferenciar por los siguientes caracteres:

1. Tallos y hojas glabras, vaina estipular con lacinias muy breves $0,75-$ $1,75 \mathrm{~mm}$ long. Cáliz siempre con 4 sépalos, corola e hipantio papilosos, corola de la flor brevistila, 4,25-5 mm long., corola de la flor longistila, 4-4,50 mm; disco papiloso; fruto papiloso; semillas no aladas.

G. krausei

1'. Tallos pubérulos a glabrescentes, hojas glabrescentes a veces escábridas, vaina estipular con lacinias más largas, 1,25-3 mm long. Cáliz con 2 sépalos, raro 4, corola e hipantio pubescentes, corola de la flor brevistila 3-3,75 mm long.; corola de la flor longistila 3,25$3,50 \mathrm{~mm}$; disco pubescente; fruto piloso; semillas complanadas, ligeramente aladas.

G. bisepala

Fig. 2.- Galianthe bisepala. A, rama; B, vaina estipular (Novara 2777); C-D, cáliz y corola de Ja flor brevistila (Cabrera 13062); E-F, cáliz y corola de la flor longistila (Schreiter 5424); G, frulo; H-J, semilla, cara dorsal, cara ventral y corte transversal (holotipo). 
Novedades en Galianthe

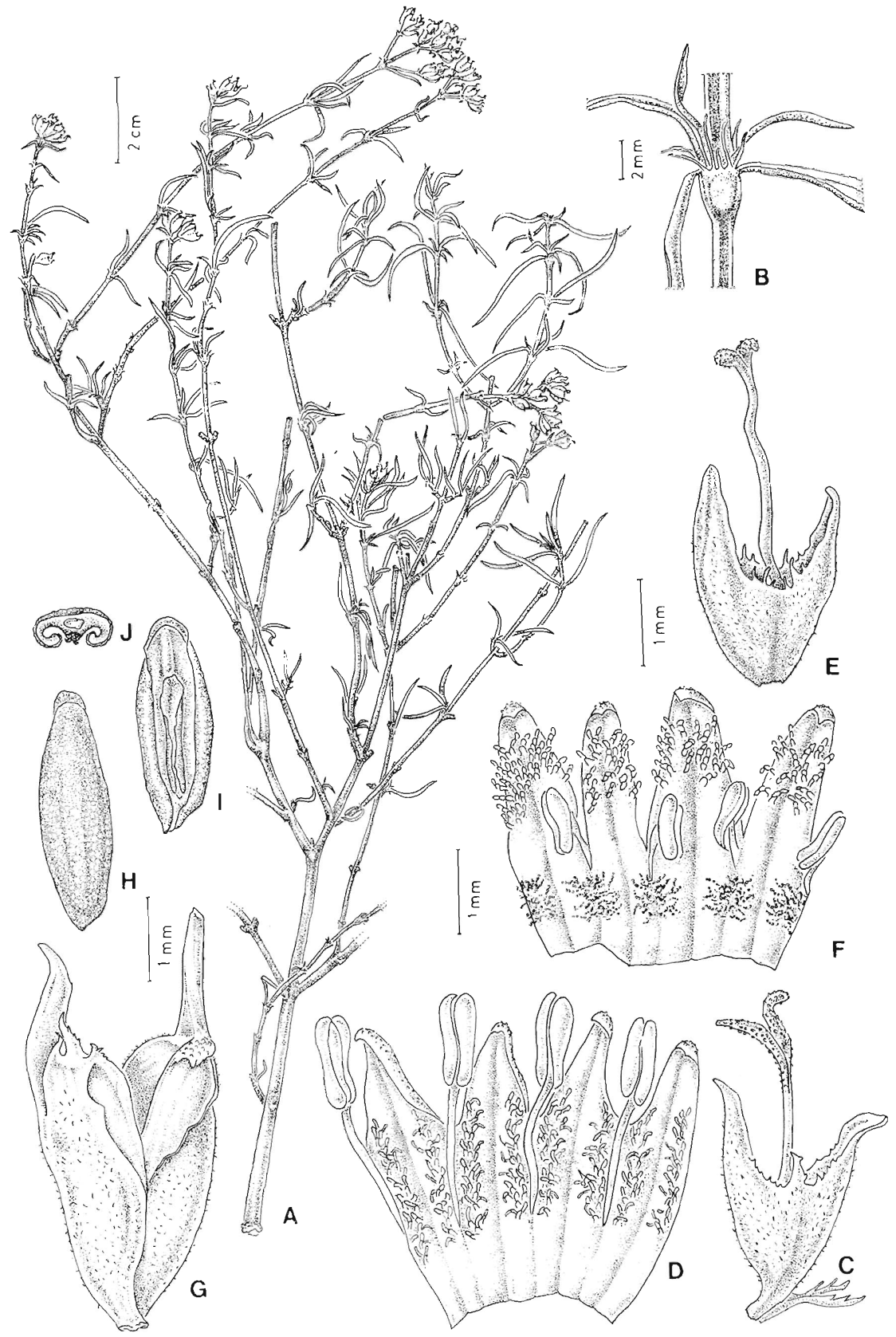




\section{Galianthe canindeyuensis Cabral nov. sp.}

Fig. 3

Suffrutex ramosissimus, $80-90 \mathrm{~cm}$ alt., caules quadrangulares pubescentes, internodiis $(0,8)-3-5 \mathrm{~cm}$ long. Foliae pseudofasciculatae, sessilae, lanceolatae vel ovalis-lanceolatae, apice acuminato, base acuta vel obtusa, utrinque pubescentes, supra venis opositis surcatis, infra plicatis 7-25 $\times 3-10 \mathrm{~mm}$. Vagina stipulari pubescens, laciniis 5-7, glabris, ferrugineis, glandulis apicalibus. Thyrsi contracti in ramis principalibus et lateralibus. Hypanthio et corolla externe pubescentibus. Disco integer pubescens. Capsula pubescens. Semina subcylindrica, dorso convexa, ventre sulcata, solum linea media strophiolum tecta.

Typus. PARAGUAY. Canindeyú, Colonia Fortuna, $8 \mathrm{~km}$ de Curuguaty, 6.V.1974, Arenas, P. 662 (Holotypus: CTES; Isotypi: CEFAPRIN, SI).

Sufrútice muy ramificado de $80-90 \mathrm{~cm}$ alt., tallo tetrágono, pubescente, con entrenudos de (0,8)-3-5 cm long. Hojas sésiles, pseudoverticiladas por la presencia de braquiblastos, de lámina lanceolada a oval-lanceolada, ápice acuminado y base aguda u obtusa, pubescentes en ambas caras, 7-25 x 3-10 mm, con 3-5 pares de venas opuestas, surcadas en el haz, en resalto en el envés. Vaina estipular pubescente, 2-3 mm, con 5-7 lacinias, filiformes, rojizas, glabras con glándulas apicales. Tirsos sobre ramas principales, densos y cortamente pedunculados. Cáliz con 4 lóbulos pubescentes de 1-1,50 mm long., con dientes interlobulares, hipantio subcilíndrico, pubescente de 1,25-2 mm long. Corola externamente pubescente, con pelos más largos sobre la cara dorsal de los lóbulos, superficie interna con dos anillos de pelos moniliformes, el inferior más denso, de pelos delgados sobre el tubo y el superior de pelos largos y gruesos sobre los lóbulos; filamentos estaminales breves, 0,48-0,50 mm, anteras 0,75-1 mm; estilo 2,25-2,50 mm, bifurcado en el ápice, ramas estigmáticas con papilas pluricelulares; disco entero, pubescente. Cápsula turbinada,

Fig. 3.- Galianthe canindeyuensis. A, planta: B. vaina estipular; C-D, cáliz y corola de la flor longistila; E, fruto; F-G, semilla cara dorsal y ventral (holotipo). 
Novedades en Galianthe

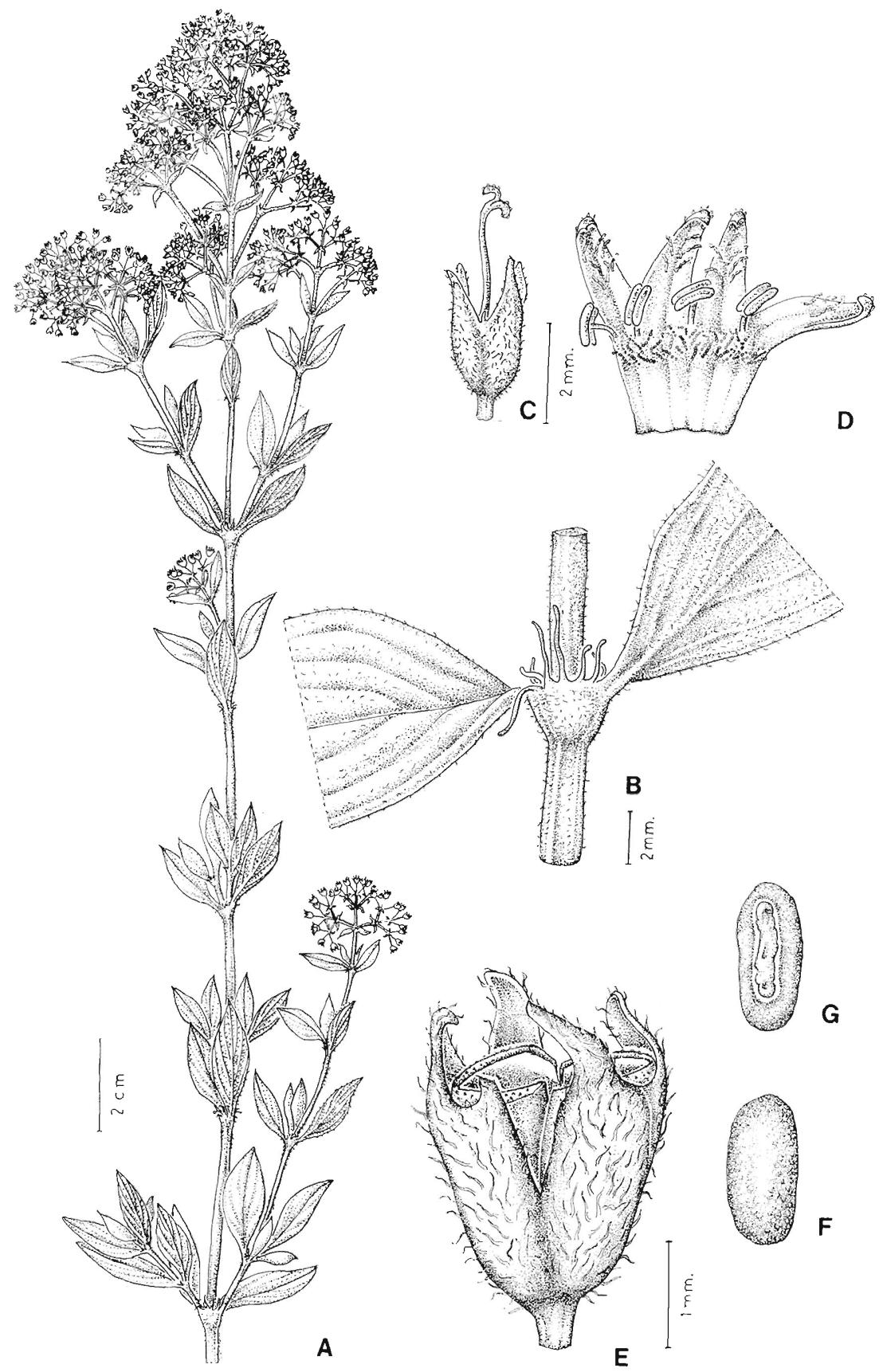


pubescente, 2-2,75 mm long. Semilla subcilíndrica, escrobiculada, 1,201,25 mm long., planoconvexa, con surco alrededor del estrofíolo.

Obs. Hasta el presente sólo se conoce el ejemplar tipo, este material presenta flores longistilas.

Los caracteres distintivos de esta nueva especie son: pubescencia en toda la planta, inflorescencia muy densa y comprimida y semillas subcilíndricas plano-convexas. Su aspecto es semejante al de Galianthe centranthoides (Cham. et Schldl.) Cabral, pero en esta especie la inflorescencia es más laxa y las semillas son complanadas y con alas apicales.

\section{Galianthe elegans Cabral nov. sp.}

Fig. 4

Suffrutex 60-65 cm alt., xilopodio, ramis principalibus ex baser et ramis pluribus lateralibus opositis. Caules subquadrangulares, glabres, fistulosae. Folicie sessilae oppositae vel pseudo-fasciculatae, ellipticae, elliptice-ovalae, utrinque glabres, 6 $11(18) \times 2-6 \mathrm{~mm}$, venis secundariis inconspicuis; vagina stipulari 1 -2 mm long., glabrescens, laciniis 3 triangulo-subulatis, lacinia centrale longiora. Thyrsi late pedunculate in ramis principalis, calyci lobulis et corolla externe micropapillatis; disco integer micropuplloso. Flos brevistyli: intus corolla, tubo medio annularipiloso moniliformis, inter lobulis pilis dispersis. Flos longistyli: intus corolla, tubo medio annulari-pilosis moniliformis, tenuis, lobo arco pilis crassis. Capsula glabra turbinata 4-6,25 mm long.; semina dorso-ventraliter complanata; alis parvis apicalibus.

Typus. BRASIL. Paraná, Vila Velha, en campo alrededor de la Iglesia, 15.I.1987, Krapovickas et Cristóbal 40875 (Holotypus: MBM; Isotypi: CTES, MO, SI).

Sufrútice de 60-65 cm alt., con xilopodio, tallo subtetrágono, fistuloso, glabro, con braquiblastos. Hojas opuestas o pseudoverticiladas, elípticas,

Fig. 4.- Galianthe elegans. A, planta; B, xilopodio; C, nudo (holotipo); D-E, cáliz y corola de la flor brevistila; F-G, cáliz y corola de la flor longistila (Moreira Filho 472); H, fruto (holotipo). 


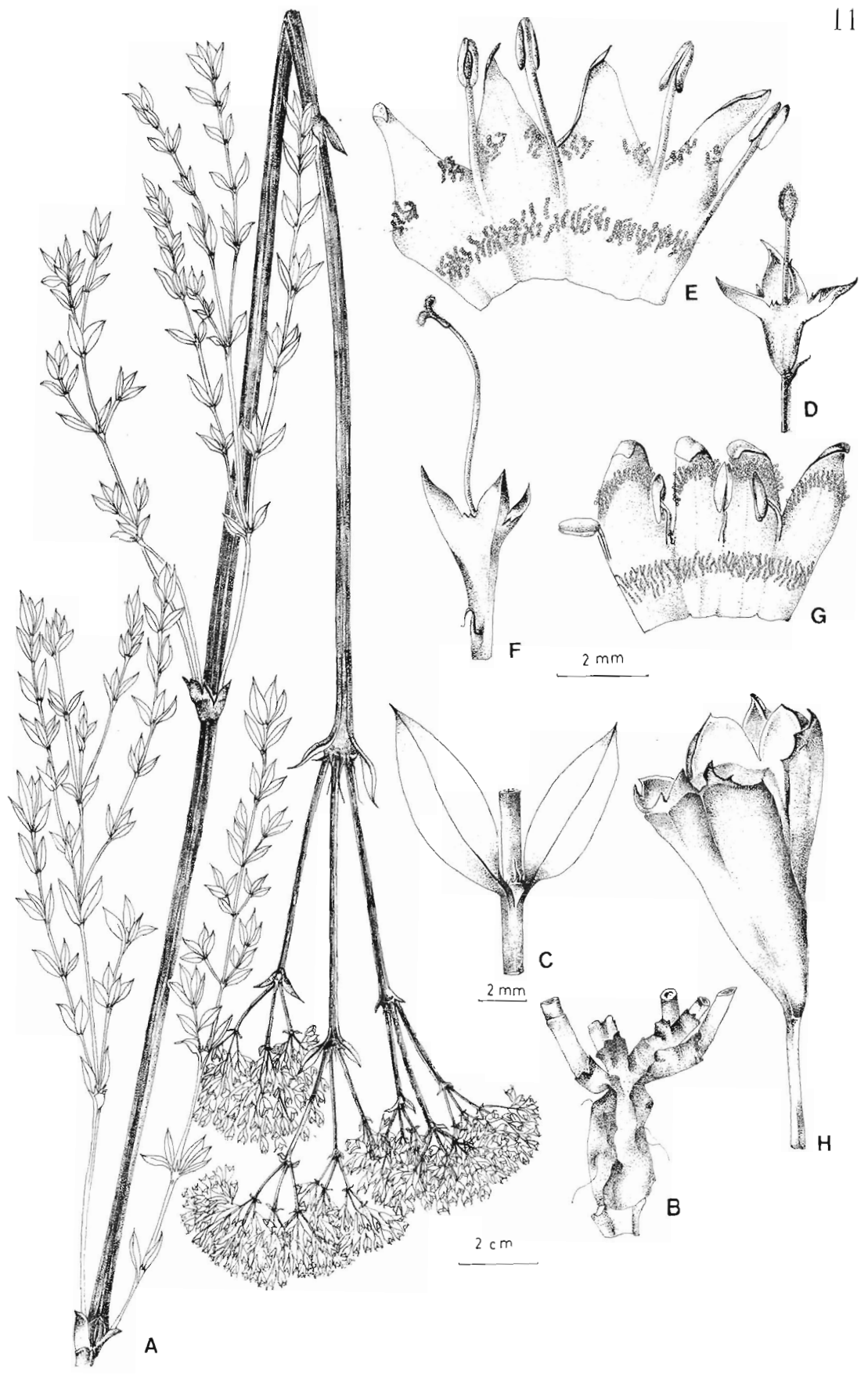


elíptico-ovadas, sésiles, ápice agudo, base obtusa o aguda, 6-11(18) x 2-6 $\mathrm{mm}$, glabras, con rafidios dispersos, vena principal prominente en el envés, venas secundarias inconspicuas, raro 2-3. Vaina estipular 1-2 mm long., glabra o con pocos pelos dispersos, con 3-4 lacinias, triangular-subuladas, con pelos cortos en la base, la del centro mayor 1-4 mm long.

Tirsos terminales, largamente pedunculados. Cáliz con 4 lóbulos triangulares, 0,75-1 mm long., con 1-2 dientes interlobulares con densas papilas, hipantio turbinado, 1,25-2 mm long. Corola blanca, externamente papilosa; disco entero micropapiloso. Flor brevistila: corola 3,5-5 mm long., lóbulos más cortos que el tubo corolino, superficie interna con un anillo de pelos moniliformes gruesos y largos sobre el tercio inferior del tubo, y escasos pelos dispersos entre los lóbulos. Estambres exertos, filamentos 1,50-2,50 mm, anteras 1-1,25 mm long.; estilo 2-2,50 mm, bífido, ramas estigmáticas lanceoladas con densas papilas pluricelulares. Flor longistila: corola 3-5 mm long.; lóbulos iguales o más largos que el tubo corolino, superficie interna, con un anillo de pelos moniliformes, delgados sobre la mitad del tubo y un arco de pelos gruesos sobre cada lóbulo; filamentos estaminales breves, anteras $1 \mathrm{~mm}$ long.; estilo 4-4,5 mm long. bifurcado en el extremo, ramas estigmáticas con papilas densas pluricelulares, en el resto del estilo papilas aisladas, simples. Fruto turbinado, glabro, 4-6, $25 \mathrm{~mm}$ long.; semillas complanadas dorsiventralmente, alas apicales.

Distribución geográfica. Esta especie brasileña vive en campos, ha sido coleccionada hasta el momento sólo en el estado de Paraná.

Paratipos. BRASIL. Paraná, Ponta Grossa, I.XI.1928, Hoehne 23269 (SP); ibid., 18.X.1968, Moreira Filho et al. 472 (CTES, UPCB).

Obs. G. elegans es afín a G. chodatiana (Hassler) Cabral, pero se diferencian principalmente porque $G$. chodatiana tiene hojas de mayor tamaño, 20-40 mm long. x 5-15 mm lat., con las venas secundarias siempre visibles, margen pubescente y a veces pelos sobre las venas del envés, también la vaina estipular es más desarrollada, de 2-5 mm long., con 4-5 lacinias de 1,5-10-(14) $\mathrm{mm}$ long. 


\section{Galianthe gertii Cabral nov. sp.}

Fig. 5

Suffrutex erectus vel decumbens $20-50 \mathrm{~cm}$ alt. Caules quadrangulares, glabres. Foliae sessilae, ovatae vel oblongo-ellipticae, discolorae, utrinque glabrae, 8-25x 2-7 mm. Vagina stipulari irregulari 3-5 lobulis. Thyrsi paucifloribus, terminalis umbelliformis, hypanthio turbinato glabro, calycis lobulis 4 triangularibus, dentibus interlobularibus, corolla liliacea vel albescens, lobi dorso apicale dense papilloso; disco integer papilloso. Flos brevistyli et flos longistyli: corolla intus 2 annularipilosis moniliformis I lobo, 1 tubo. Capsula glaber turbinata.

Holotypus. BRASIL. Paraná, Mun. Campina Grande do Sul, Serra Ibitiraquire, 22.I.1970, Gert Hatschbach 23388 (MBM).

Sufrútice erecto o decumbente, de $20-50 \mathrm{~cm}$ alt., tallo tetrágono, glabro, brotes axilares en todos los nudos, entrenudos, 0,5-5,5 cm long. Hojas sésiles, 8-25 x 2-7 mm, ovado a elíptico-oblongas, de ápice agudo y base obtusa, bordes revolutos, subcoriáceas, glabras, con puntos brillantes en ambas caras, discoloras, vena media deprimida en el haz y prominente en el envés, y 2-3 pares de venas secundarias poco visibles. Vaina estipular irregular con 3-5 lóbulos triangular-lanceolados, glabros, con puntos brillantes, 1,25-3,75 mm, el central de mayor longitud.

Tirso terminal umbeliforme, paucifloro. Cáliz con 4 lóbulos triangulares, con diminutos dientes intercalares, hipantio turbinado, glabro, 0,75$1,50 \mathrm{~mm}$ long. Corola lila o blanquecina, externamente glabra, con densas papilas en el dorso hacia el extremo de los lóbulos; disco entero, papiloso. Flor brevistila: corola 4,5-6,25 mm, con lóbulos iguales o más cortos que el tubo corolino, superficie interna con pelos moniliformes delgados sobre el tubo hasta la base de los lóbulos y pelos más gruesos sobre el tercio inferior de los lóbulos; filamentos estaminales de 1-1,75 mm long. y anteras de 1-1,25 mm; estilo 2-2,75 mm, bifurcado en su tercio superior, ramas estigmáticas con papilas densas. Flor longistila: corola 3,75-5 mm long., con lóbulos iguales o más cortos que el tubo corolino, superficie interna con 2 anillos de pelos moniliformes, uno, de pelos delgados, sobre el tercio inferior del tubo y otro, de pelos más gruesos, en arco sobre la mitad de los lóbulos; filamentos estaminales breves y anteras de 0,71-1,25 mm; 
estilo 4-4,5 mm, dividido en su extremo, con ramas estigmáticas recurvadas. Fruto turbinado, glabro. Semilla no vista.

Distribución geográfica. Esta especie brasileña fue encontrada hasta el presente sólo en el estado de Paraná, en morros, entre 1000-1700 m s.m.

Paratipos. BRASIL. Paraná, Morretes, Serra Marumbi, Picada Frontal, 15.I.1950, Imaguirre 1734 (LIL); 27.II.1970, Hatschbach 23935 (MBM); Campina Grande do Sul, Serra Capivari, 8.II.1971, Hatschbach 26316 (MBM); Pico Caratuva, 29.XII.1967, Hatschbach 18206 (MBM).

Obs. G. gertii se individualiza por la vaina estipular irregular terminada en 3-5 lóbulos triangular-lanceolados y también por los tirsos umbeliformes paucifloros de flores lilas o blanquecinas.

El epíteto específico es un homenaje al botánico brasileño Gert Hatschbach, quien coleccionó el material elegido como tipo.

\section{Galianthe grandifolia Cabral nov. sp.}

Fig. 6

Suffrutex 0,50-1,80 m alt, xilopodio, base paucis ramificationibus, caules simplices, fistulosi, cylindrices vel subquadrangulares, internodiis $2-12 \mathrm{~cm}$ long. Foliae sessilae, subcoriaceae, oppositae vel pseudofasciculatae, lanceolatae, ellipticolanceolatae, supra glabra vel puberula, subtus pubescens 40-105 × 5-40 mm, 5-6 nervis lateralibus conspicuis; vagina stipulari pubescens 3-10 mm long., laciniis 6-7 filiformibus. Thyrsi terminales late pedunculatae, hypanthio pubescente, calycis lobulis 4-triangulari-acutis papillosis, dentibus interlobularibus, corolla externe papillosa, intus 2 annulari-pilosa moniliforme: 1 in lobulo, 1 in tubo, disco integer pubescente. Capsula pubescens 4,25-5 mm long., semina 3,25-3,50 $\mathrm{mm}$ long., complanata, alis parvis apicalibus.

Typus. BRASIL. Minas Gerais, Rio Bicudo, ca. 20 km W de Corinto, 325 m s.m., 3-III-1970, H.S.Irwin, S.F. Fonseca, R. Souza, R. Reis dos Santos, J. Ramos 26820 (RB).

Fig. 5.- Galianthe gertii. A, planta; B, vaina estipular; C, flor brevistila; D-E, cáliz y corola de la flor brevistila (holotipo); F, flor longistila; G-H, cáliz y corola de la flor longistila (Hatschbach 26316). 


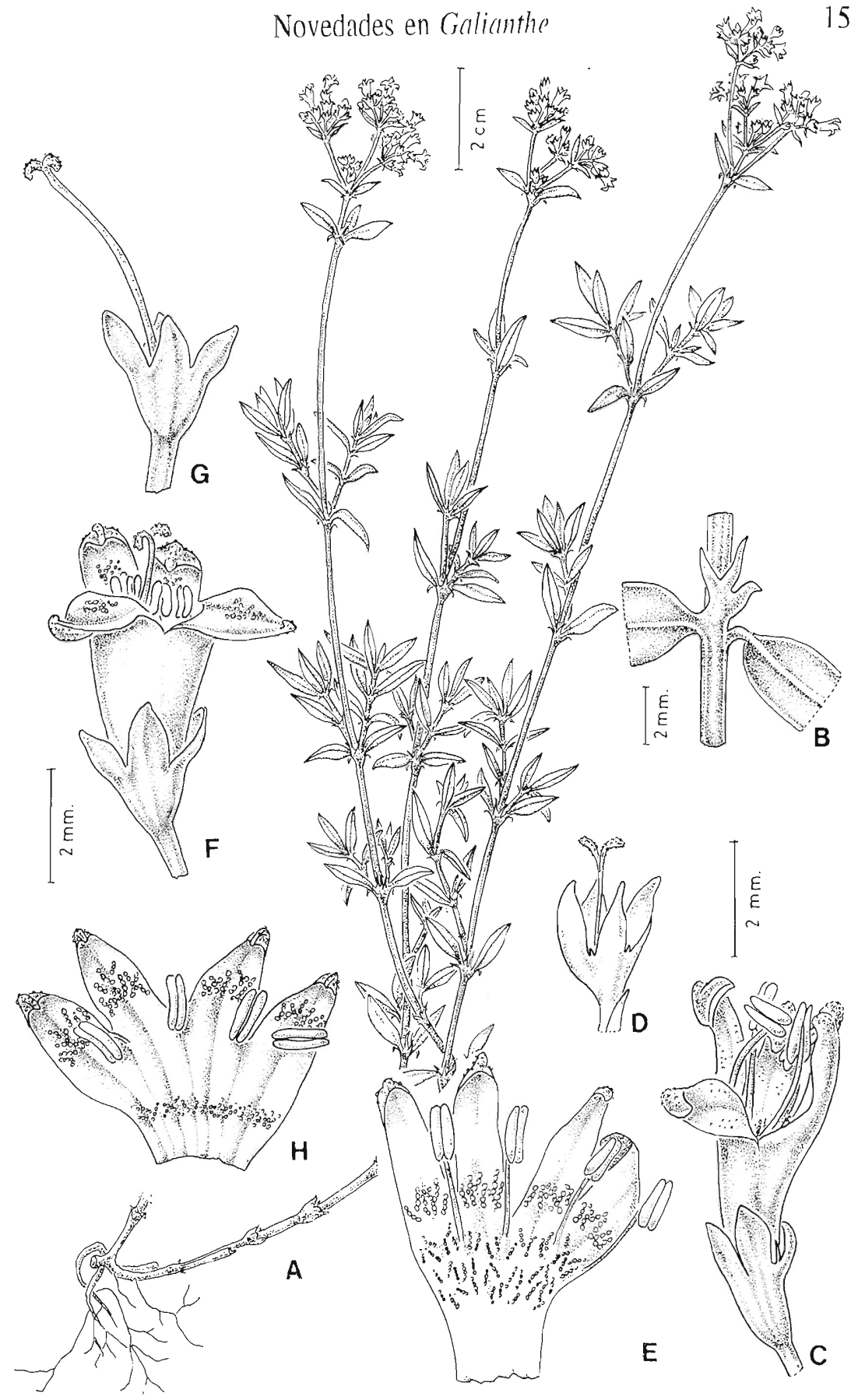


Sufrútice erecto de 0,50-1,80 m de alt., con xilopodio; tallo simple raro ramificado, fistuloso, cilíndrico o subtetrágono con ángulos romos, pubérulos o diversifacial, entrenudos $2-12 \mathrm{~cm}$ long. Hojas subcoriáceas, opuestas, a veces pseudoverticiladas, sésiles, elíptico-lanceoladas o lanceoladas, 40-105 x 5-40 mm, haz glabro a pubérulo, envés pubescente con pelos densos sobre las venas, vena media y secundarias con ángulo de divergencia de $10^{\circ}-20^{\circ}$, plegado-nervosas, impresas en el haz, prominentes en el envés. Vaina estipular pubescente 3-10 mm long., con 6-7 lacinias filiformes, 3-8 mm long., la del centro de mayor tamaño.

Tirso terminal, largamente pedunculado. Cáliz con 4 lóbulos de 1-1,75 $\mathrm{mm}$, triangulares, papilosos con dientes interlobulares, hipantio pubescente, 2-3 mm long. Corola blanca, de superficie exterior densamente papilosa, con cresta media en el dorso de los lóbulos; disco entero, pubescente. Flor brevistila: corola 4,50-5 mm, con lóbulos más largos que el tubo corolino, superficie interna con dos anillos de pelos moniliformes, uno de pelos delgados y cortos sobre la mitad del tubo y otro de pelos gruesos y largos, sobre la mitad superior de los lóbulos; filamentos estaminales papilosos, 1-1,50 mm y anteras 1,50-1,75 mm long.; estilo 2,5-3 mm, bifurcado en la mitad, con ramas estigmáticas lineares con papilas unicelulares, cortas y gruesas. Flor longistila: corola 3,50-4,5 mm, con lóbulos iguales o más largos que el tubo, superficie interna con dos anillos de pelos moniliformes, uno de pelos delgados sobre la mitad del tubo y otro de pelos densos, gruesos y más largos sobre los lóbulos; filamentos estaminales muy breves, anteras 1-1,25 mm; estilo 3-5 mm, bifurcado en su quinto superior, ramas estigmáticas lineares con papilas multicelulares. Cápsula turbinada, pubescente, 4,25-5 mm long.; semillas 3,25-3,50 mm long., complanadas, con pequeñas alas agudas, apicales, cara dorsal convexa, cara ventral cóncava, con amplio surco alrededor del estrofíolo.

Fig. 6.- Galianthe grandifolia. A, planta (holotipo); B, flor brevistila; C-D, cáliz y corola de la flor brevistila (Kirkbride 5334); E, flor longistila; F-G, cáliz y corola de la flor longistila (holotipo). 


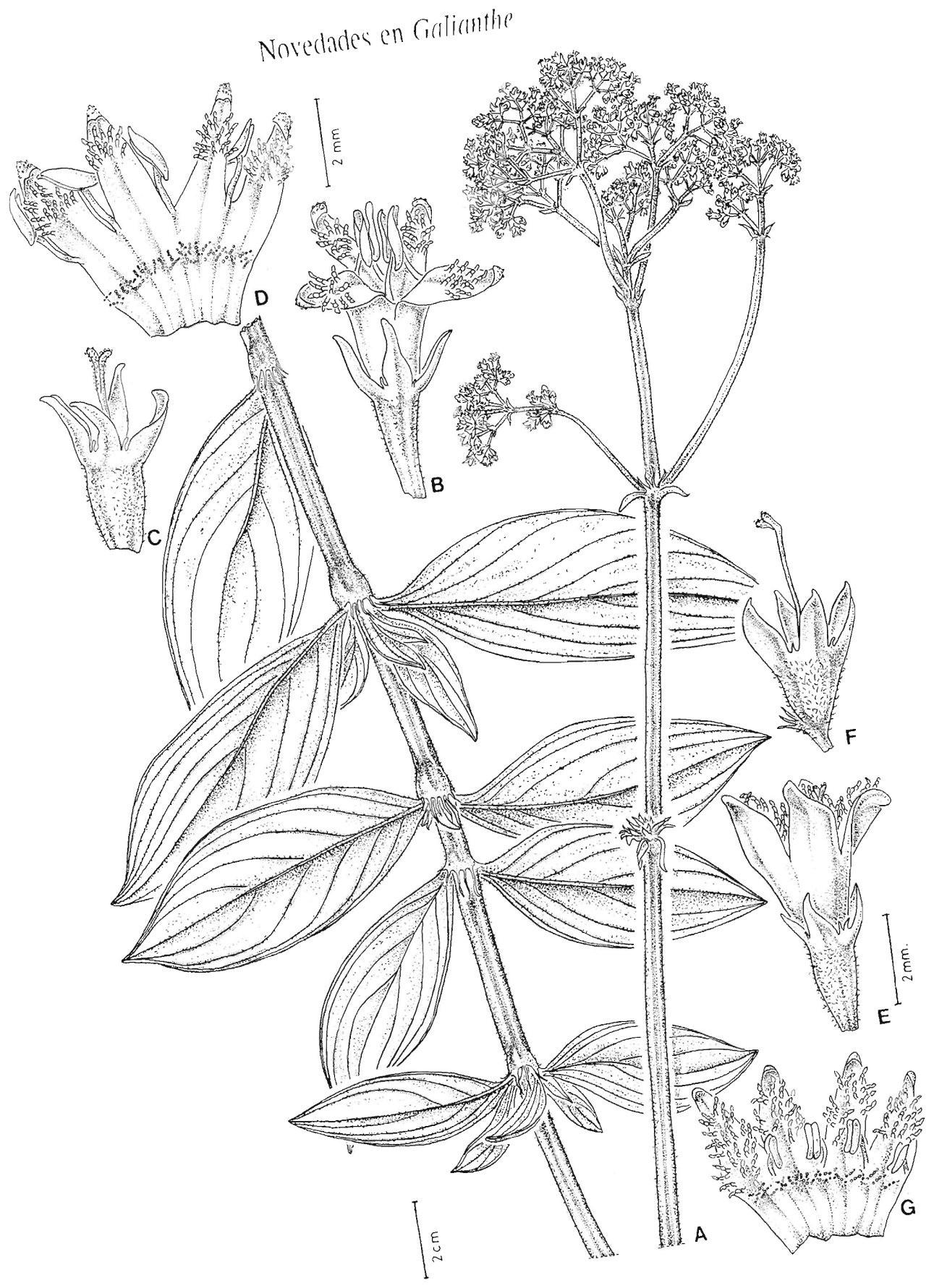


Distribución geográfica. Se trata de una especie encontrada en Brasil, en el cerrado, entre 525 -1300 m s.m. en los estados de Mato Grosso, Distrito Federal, Goiás y Minas Gerais.

Paratipos. BRASIL. Mato Grosso, $270 \mathrm{~km} \mathrm{~N}$ de Xavantina, 29.V.1968, Santos et al. 1566 (RB); $86 \mathrm{~km} \mathrm{~N}$ de Xavantina, 1.VI.1966, Irwin et al. 16377 (RB). Distrito Federal, entre Brasilia y Niquelandia, cerrado, 10.V.1963, Pires et al. 9731 (RB); Cabeça de Veado, $1 \mathrm{~km} \mathrm{~S}$ de Escola Faziendeira por estrada, $15^{\circ} 53^{\prime} \mathrm{S}, 47^{\circ} 50^{\prime}$ W, 1.V.1980, Kirkbride 3162 (CTES, MBM, RB); Perto de Corrego Vandinha, $1 \mathrm{~km} \mathrm{~S}$ de Brazilandia, 5.V.1982, Kirkbride 4765 (CTES, MBM. RB); $2 \mathrm{~km} \mathrm{NE}$ de Corrego Sitio Novo, 13.VI.1983, Kirkbride 5334 (CTES); Brasilia, 1.IV.1958, Lima 58-2979 (RB): Goiás, 4 km de Aparecida de Goiás-Goiania, 5.III.1966, Rizzo 22 (RB); $10 \mathrm{~km} \mathrm{NW}$ de Formosa, 29.IV.1966, Irwin et al. 15466 (RB); Serra Dourada, 21.I.1967, Duarte 10373 (RB); 8 km S de Cavalcante, 7.V.1969, Irwin et al. $24002(\mathrm{RB}) ; 16 \mathrm{~km} \mathrm{~N}$ de Pires Belo, 30.I.90, Arbo et al. 3084 (CTES, HRCB). Minas Gerais, Serra do Espinhaço, 13.I.1969, Irwin et al. 21857 (RB); 7 km NE de Diamantina, 29.I.1969, Irwin et al. 22835 (RB); ibid., 18.V.90, Arbo et al. 4432 (CTES, SPF); ibid., 19.V.90, Arbo et al. 4459 (CTES, SPF): 36 km NE de Francisco Sá, 12.II.1969, Irwin et al. 23179 (RB): 4 km N de São Joao da Chapada, 23.III.1970, Irwin et al. 28166 (RB), ibid., 19.V.90, Arbo et al. 4459 (CTES, SPF): $42 \mathrm{~km} \mathrm{~S}$ de Paracatu, Serra Branca, 31.I.90, Arbo et al. 3234 (CTES, HRCB).

Obs. Galianthe grandifolia es semejante a Galianthe centranthoides (Cham. et Schldl.) Cabral pero en esta especie las plantas son más ramificadas, densamente pubescentes, con hojas de menor tamaño, 3055(70) mm long. x 3-12(28) mm lat. y corolas con pelos moniliformes densos en la superficie interna.

\section{Galianthe latistipula Cabral nov. sp.}

Fig. 7

Suffrutex $45-95 \mathrm{~cm}$ alt., xilopodio, base paucis ramificationibus. Caules simplices, fistulosi, cylindrici vel subquadrangulares, internodiis $3-6,5 \mathrm{~cm}$ long. Foliae sessilae pseudofasciculatae, lanceolatae, elliptico-lanceolatae, coriaceae, utrinque glabrae, 15-60 × 3-15 mm, nervis lateralibus inconspicuis; vagina stipulari glabra 5-6,25 nm long., lóbulo medio triangulare longe acuminato, in margine laciniis dissimilibus. Thyrsi corymbiformi, glabres; corolla externe glabra, facie interna 2 annulis-pilosis moniliformis: 1 in lobulo, 1 in tubo: calycis 
4 lobulis triangularibus, dentibus inter lobularibus, hypanthium turbinatum glabrum 1,50-1,75 mm long.; disco integer papilloso. Capsula glaber turbinata 2,50-3,5 mm long.; semina complanata 2-2,75 mm long., alis parvis apica libus.

Typus. BRASIL. Rio Grande do Sul, Vila Oliva, p. Caixas, 8.II.1955, Rambo, B. 56661 (Holotypus: PACA; Isotypi: CTES, SI).

Sufrútice erecto, de $45-95 \mathrm{~cm}$ alt., con xilopodio, pucas ramificaciones basales, tallos simples, glabros, fistulosos, cilíndricos o subtetrágonos con ángulos romos, entrenudos 3,5-6,5 cm long. Hojas pseudoverticiladas, lanceoladas, elíptico-lanceoladas, sésiles, coriáceas, glabras en ambas caras, 15-60 × 3-15 mm, con cinco pares de venas secundarias, inconspicuas en el haz, apenas marcadas en el envés. Vaina estipular glabra, con lacinias desiguales, 5-6,25 mm long., con un diente medio, triangular, largamente acuminado.

Tirsos terminales, glabros, corimbiformes, flores sésiles. Cáliz con 4 lóbulos triangulares, de 1,50-1,75 mm long., con dientes interlobulares, hipantio turbinado, glabro, 1,50-1,75 mm long. Corola blanca externamente glabra; disco entero papiloso. Flor brevistila: corola 3,5-5 mm long., con lóbulos iguales o más cortos que el tubo corolino, superficie interna con dos anillos densos de pelos moniliformes, uno de pelos cortos y delgados sobre la mitad del tubo y otro de pelos gruesos sobre el tercio inferior de los lóbulos; filamentos estaminales de 0,5-1 mm long. y anteras de 1,25$1,50 \mathrm{~mm}$; estilo 1,5-2,5 mm long., bifurcado desde la mitad, ramas estigmáticas con papilas densas. Flor longistila: corola 3,50-5 mm, con lóbulos más largos que el tubo corolino, superficie interna con dos anillos de pelos moniliformes, uno de pelos delgados sobre el tubo y otro de pelos gruesos sobre la mitad de los lóbulos; filamentos estaminales muy breves y anteras 1-1,25 mm long.; estilo 4-5 mm, bífido en el tercio superior, ramas estigmáticas lineares, densamente papilosas. Cápsula glabra, turbinada, 2,5-3,5 mm long.; semillas complanadas, 2-2,75 mm long., con pequeñas alas apicales.

Distribución geográfica. Esta especie brasileña vive en campos, en Rio Grande do Sul y al sur de Santa Catarina. 
Paratipos. BRASIL. Rio Grande do Sul, Soledade, 13.II.1951, Rambo 50047 (CTES, LIL, PACA); Nonoai, III.1945, Rambo 28228 (PACA); Lagoa Vermelha, I.1943, Rambo 11408 (PACA); Bom Jesús, 5.I.1947, Rambo 34859 (PACA, SI); Passo do Inferno, 9.I.1955, Rambo 56578 (CTES,PACA); ibid., I.III.1965, Brescia y Marchesi 4089 (MVFA); Vacaria, 15.I.1942, Rambo 8763 (PACA); ibid., 5.1.1978, Miotto 805 (ICN); Fundo Feio, 28.II.1964, Schultz 3990 (ICN). Santa Catarina, Passo do Socorro, Lajes, 3.1I.1963, Reitz 6511 (MBM).

Obs. Considerando el tallo simple, las hojas glabras y la inflorescencia terminal, Galianthe latistipula se asemeja a Galianthe fastigiata Griseb., pero en esta última especie la vaina estipular termina en lacinias sin diente medio que sobresalga; la superficie interna de la corola está cubierta de pelos moniliformes densos, donde es difícil distinguir dos anillos y las semillas son subcilíndricas.

\section{Galianthe linearifolia Cabral nov.sp.}

Fig. 8

Suffrutex ramosissimus, $15-60 \mathrm{~cm}$ alt.; xilopodio. Caules quadrangulares, pubescentes. Foliae pseudofasciculatae sessilae lineares 5-10 x 0,25-2 mm, utrinque pubescentes. Vagina stipularis brevis pubescens, laciniis 3-5 inaequalibus. Thyrsi terminalis late pedunculate. Capsula glaber turbinata. Semina dorso ventrali complanata, alis parvis apicalibus.

Tipus. PARAGUAY. Alto Paraná, $54^{\circ} 35^{\prime} \mathrm{W}, 25^{\circ} 17^{\prime} \mathrm{S}$, Ea. Santa Elena, Pira Pyta, 11.X.90, A. Schinini et G. Caballero Marmori 27227 A brevistila, 27227 B longistila (Holotypus: CTES, Isotypi: G, MO).

Sufrútice, ramificado, formando matas, pubescente, $15-60 \mathrm{~cm}$ de alt., con xilopodio, tallos tetrágonos, pubescentes. Hojas sésiles, lineares, pseudoverticiladas, por la presencia de braquiblastos axilares, 5-10 x 0,25$2 \mathrm{~mm}$, margen revoluto, pubescentes en ambas caras. Vaina estipular bre-

Fig. 7.- Galianthe latistipula. A, planta; B, vaina estipular (holotipo); C, flor brevistila; D-E, cáliz y corola de la flor brevistila (Rambo 50047); F, flor longistila; $\mathrm{G}-\mathrm{H}$, cáliz y corola de la flor longistila; I, fruto (isotipo CTES). 


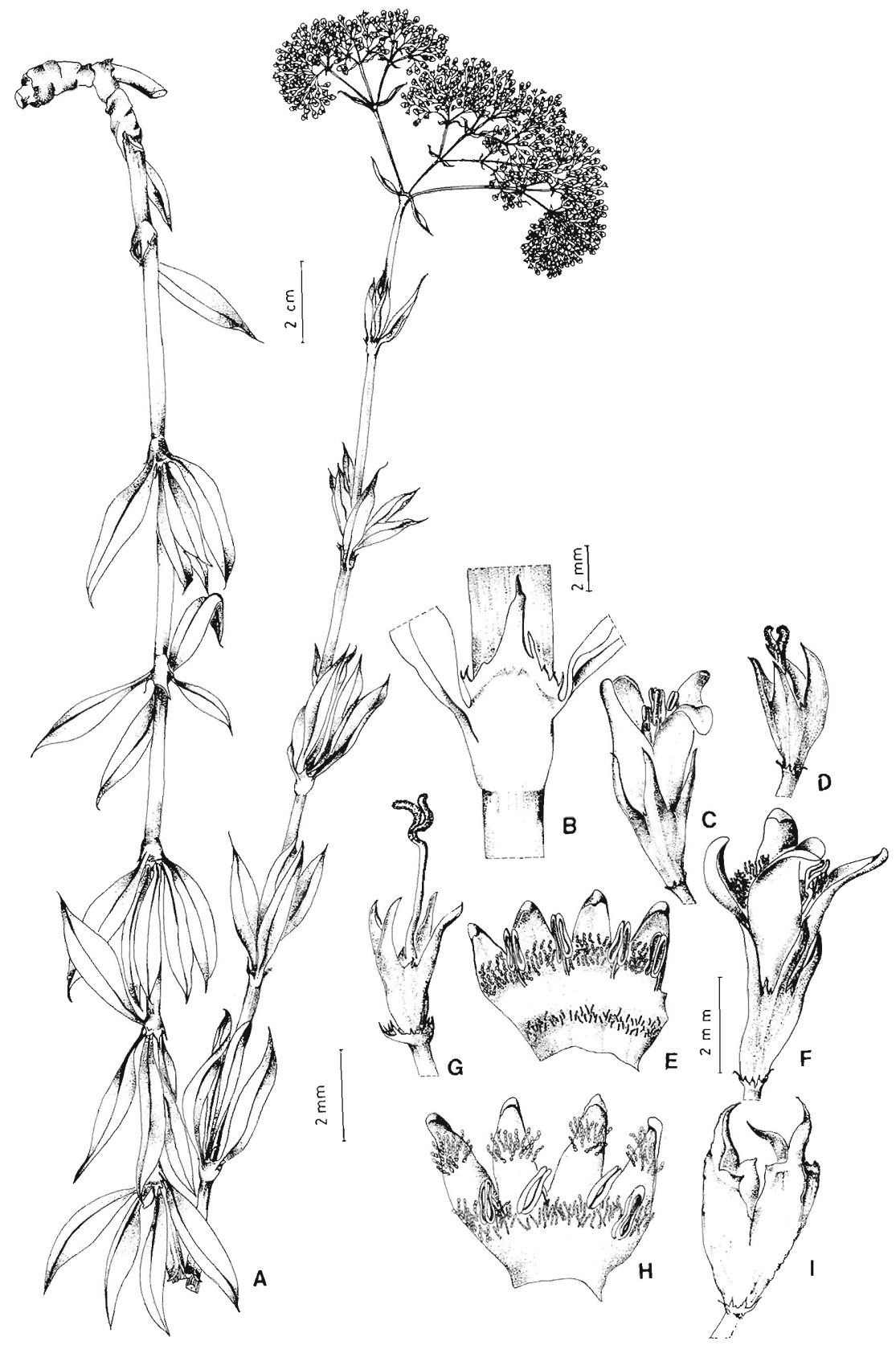


ve, 0,50-4 mm, pubescente, con 3-5 lacinias desiguales, lineares a triangular-subuladas, 1-6 mm long. Tirsos corimbiformes, largamente pedunculados. Cáliz de lóbulos triangular-acuminados, de 0,75-1 mm long., con dientes interlobulares papilosos; hipantio 1,25-1,75 mm long. Corola blanca, externamente papilosa; disco entero, papiloso. Flor brevistila: corola 2,3-3,75 mm, lóbulos más cortos que el tubo corolino, superficie interna con un arillo de pelos moniliformes en el tercio inferior del tubo y papilas en la mitad superior de los lóbulos; estambres exertos, filamentos 0,5- $\mathrm{l} \mathrm{mm}$, anteras $0,75-1 \mathrm{~mm}$; estilo $1,50-2 \mathrm{~mm}$, con papilas pequeñas unicelulares, ramas estigmáticas con papilas densas pluricelulares. Flor longistila: corola 3-4,50 mm long., con lóbulos iguales o más cortos que el tubo corolino, superficie interna, con un anillo de pelos moniliformes delgados sobre el cuarto inferior del tubo y pelos moniliformes gruesos en arco sobre los lóbulos, el resto papiloso; filamentos estaminales breves, anteras 0,5-1 mm; estilo 2,50-3,75 mm, ramas estigmáticas con papilas pluricelulares, el estilo con papilas unicelulares simples, anchas y cortas. Fruto glabro, turbinado 3-5 mm long.; semillas complanadas dorsiventralmente 2,5-3 mm long., alas apicales.

Distribución geográfica. Esta especie vive en campos altos, en Paraguay, en el departamento Alto Paraná y en la Argentina en la provincia de Misiones.

Paratipos. PARAguAy. Alto Paraná, Reserva Biológica, Tatí Yupí, 24.IX.1980, Caballero Marmori 860 (CTES). ARGENTINA. Misiones, Apóstoles, Azara, Spegazzini s/n (LP).

Obs. G. linearifolia es una especie inconfundible por formar matas, presenta ramas basales y laterales con braquiblastos muy reducidos, hojas lineares pubescentes, e inflorescencias largamente pedunculadas.

Fig. 8.- Galianthe linearifolia. A, planta; B, vaina estipular; C-D, cáliz y corola de la flor longistila; E-F, corola y cáliz de la flor brevistila; G-H, semilla cara ventral y dorsal (holotipo). 


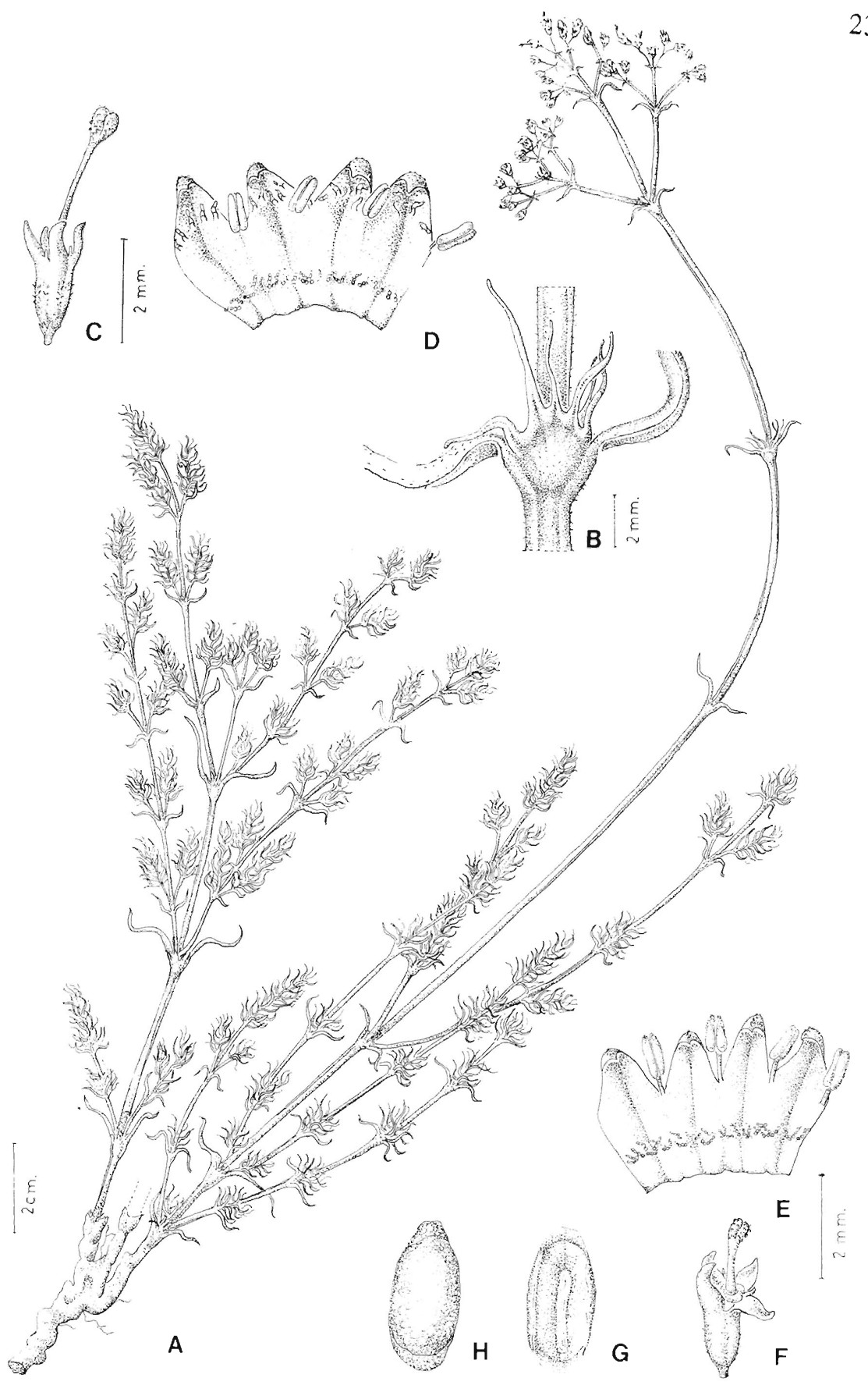




\title{
Galianthe parvula Cabral nov. sp.
}

\author{
Fig. 9
}

Suffrutex ramosissimus $20-25 \mathrm{~cm}$ alt., xilopodio. Caules quadrangulares, glabres, internodiis $1-3,5 \mathrm{~cm}$ long. Folii sessiles ellipticae, elliptico-lanceolatae, utrinque glabrae, $12-25 \times 4-10 \mathrm{~mm}$. Vagina stipulari puberula $1,50-2 \mathrm{~mm}$, laciniis 5 6 inclequalibus, glabris $0,75-3,75 \mathrm{~mm}$ long. Thyrsi breves in ramis principalis et lateralibus. Hypanthio turbinato $1,25-1,50 \mathrm{~mm}$ long., irregulariter pubescentibus. Corolla externe micropapillata, papillis crassibus et densibus, intus 2 annulari-pilosis moniliformis: I lobus, I tubo. Disco integer puberulus.

Typus. PARAGUAY. Amambay, Sierra de Amambay, Estrella, I. 1908, T. Rojas, Hassler 10082 (Holotypus: G).

Sufrútice, muy ramificado, de $20-25 \mathrm{~cm}$ alt., con xilopodio, tallos glabros, tetrágonos con aristas muy marcadas, entrenudos $1-3,5 \mathrm{~cm}$ long. Hojas sésiles, 12-25 x 4-10 mm, elípticas o elíptico-lanceoladas, de base aguda y ápice agudo a atenuado, glabras en ambas caras, a veces, con pelos dispersos sobre el nervio central en el envés, con 4-5 pares de venas secundarias subopuestas, con ángulo de divergencia de $15^{\circ}-20^{\circ}$. Vaina estipular pubérula 1,50-2 mm, con 5-6 lacinias filiformes, glabras, con glándulas apicales, de 0,75-3,75 mm long., la central de mayor tamaño. Tirsos breves terminales, corimbiformes. Cáliz con 4 lóbulos triangulares, de 1,25$2 \mathrm{~mm}$ long. con dientes interlobulares; hipantio 1,25-1,50 mm long., turbinado, irregularmente pubescente. Corola blanca, papilosa, papilas más gruesas sobre la superficie externa de los lóbulos; disco entero, pubérulo. Flor brevistila: corola 4,5-5 mm long., con lóbulos iguales o más cortos que el tubo, superficie interna con dos anillos de pelos moniliformes, uno inferior, de pelos delgados y cortos, sobre la mitad del tubo, y otro, de pelos más gruesos, sobre los lóbulos; estambres con filamentos papilosos, 1 $2 \mathrm{~mm}$ y anteras 0,75-1,25 mm long.; estilo 2-2,75 mm, ramas estigmáticas con papilas en la cara ventral. Flor longistila: corola 3-3,75 mm long., con

Fig. 9.- Galianthe parvula. A, tallo florífero y xilopodio; B, vaina estipular; C. flor brevistila; D-E, cáliz y corola de la flor brevistila (holotipo); F, flor longistila, G-H, corola y cáliz de la flor longistila (Hatschbach 47282). 


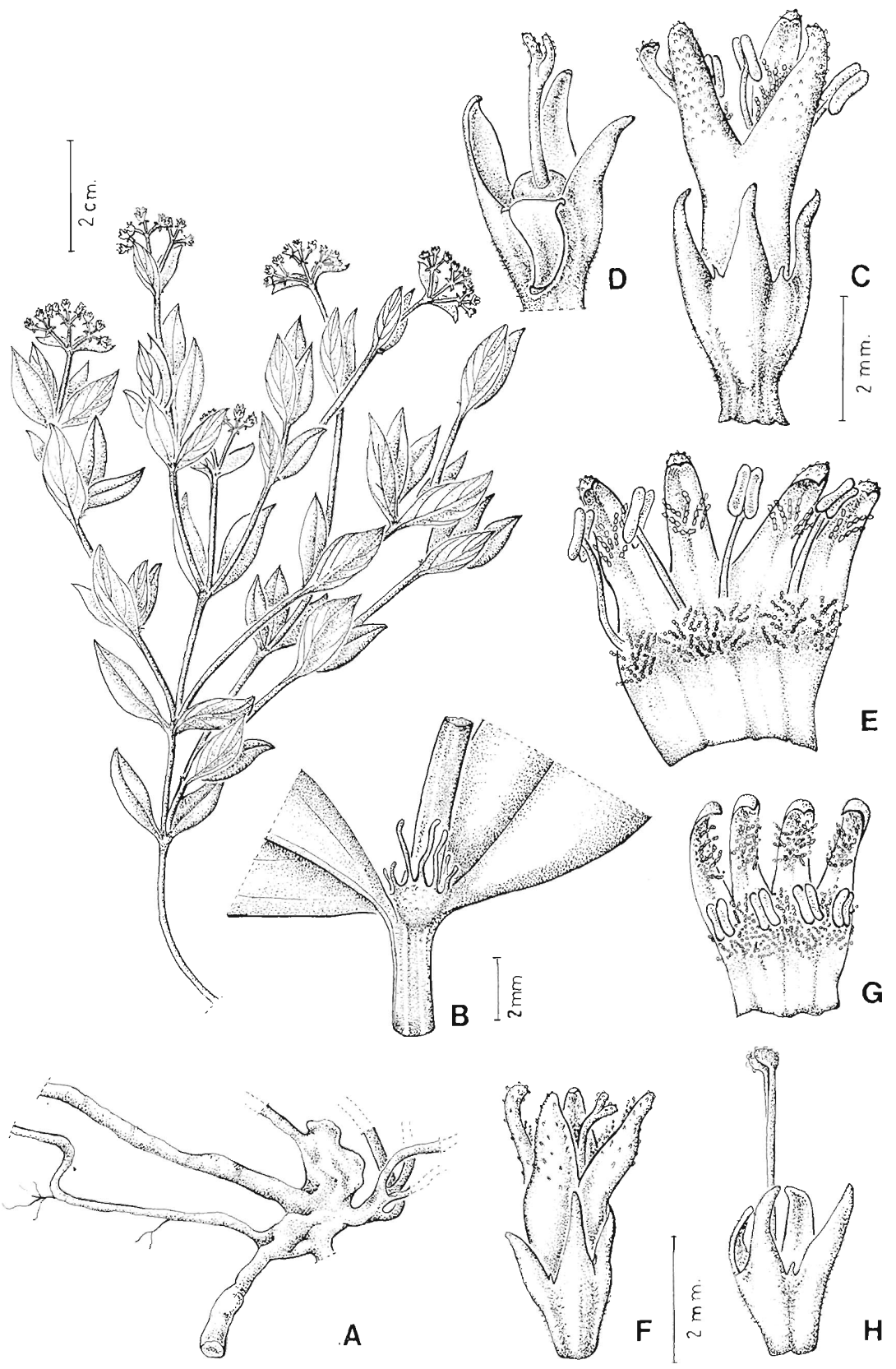


lóbulos iguales o más largos que el tubo corolino, superficie interna con dos anillos de pelos moniliformes, uno inferior, de pelos cortos y delgados, sobre la mitad superior del tubo y otro, de pelos largos y gruesos, en los lóbulos; filamentos estaminales breves, anteras 0,70-1 mm long.; estilo 3-4 $\mathrm{mm}$, ramas estigmáticas con papilas densas hacia el extremo.

Distribución geográfica. Especie colectada hasta el momento sólo en Paraguay, en campos arenosos del departamento Amambay.

Paratipos. PARAgUAY. Amambay, El Buracón, $30 \mathrm{~km} \mathrm{~W} \mathrm{de} \mathrm{Pedro} \mathrm{Juan} \mathrm{Ca-}$ ballero, 15.XII.1983, Hatschbach 47282 (MO).

Obs. Galianthe parvula se identifica fácilmente por su escasa altura, es la especie de menor crecimiento de todas las descriptas hasta el momento, y también por ser un sufrútice muy ramificado, con tirsos paucifloros corimbiformes, cortamente pedunculados en ramas principales y laterales.

\section{Galianthe pseudopeciolata Cabral nov. sp.}

Fig. 10

Suffrutex 1-1,70 m altus, xilopodio; caules subquadrangulares, fistulosae, glabres, internodiis $1-15 \mathrm{~cm}$ long. Foliae lanceolatae vel oblongo-lanceolatae, pseudopeciolatae, basi decurrente, apice acuto vel attenuato, supra glabra, subtus in margine foliae et in venis pilis brevibus antrorsis, subtus plicato-nervosis, 30-130 $\times 2-15 \mathrm{~mm}$. Vagina stipulari glabra vel scabrida $2-8 \mathrm{~mm}$ long., laciniis 7-12 linearibus, filiformibus $0,5-2,5 \mathrm{~cm}$ long. Thyrsi late corimbiformi hypanthio turbinato glabro, rafidiis sparsis 1-1,50 mm long., calycis lobulis 4-triangularibus-subulatis 1,25-2,6 mm, dentibus interlobularibus, corolla lobi dorso apicale dense papilloso. Disco integer papillosus. Capsula glaber turbinata, semina 1,30-2,75 mm long., alis parvis apicalibus, ventre plano sulcato circum strophiolo, dorso convexo.

Typus. PARAGUAY. Amambay, Sierra de Amambay, 1. 1908, T. Rojas, Hassler 10102 (Holotypus: G; Isotypus: LIL).

Fig. 10.- Galianthe pseudopeciolata. A, planta; B, tlor brevistila, C-D, cáliz y corola de la flor brevistila (holotipo): E, flor longistila; F-G, cáliz y corola de la flor longistila; H, fruto; I-K, semilla cara dorsal, ventral y corte transversal (Schwarz 11791). 
Novedades en Galianthe

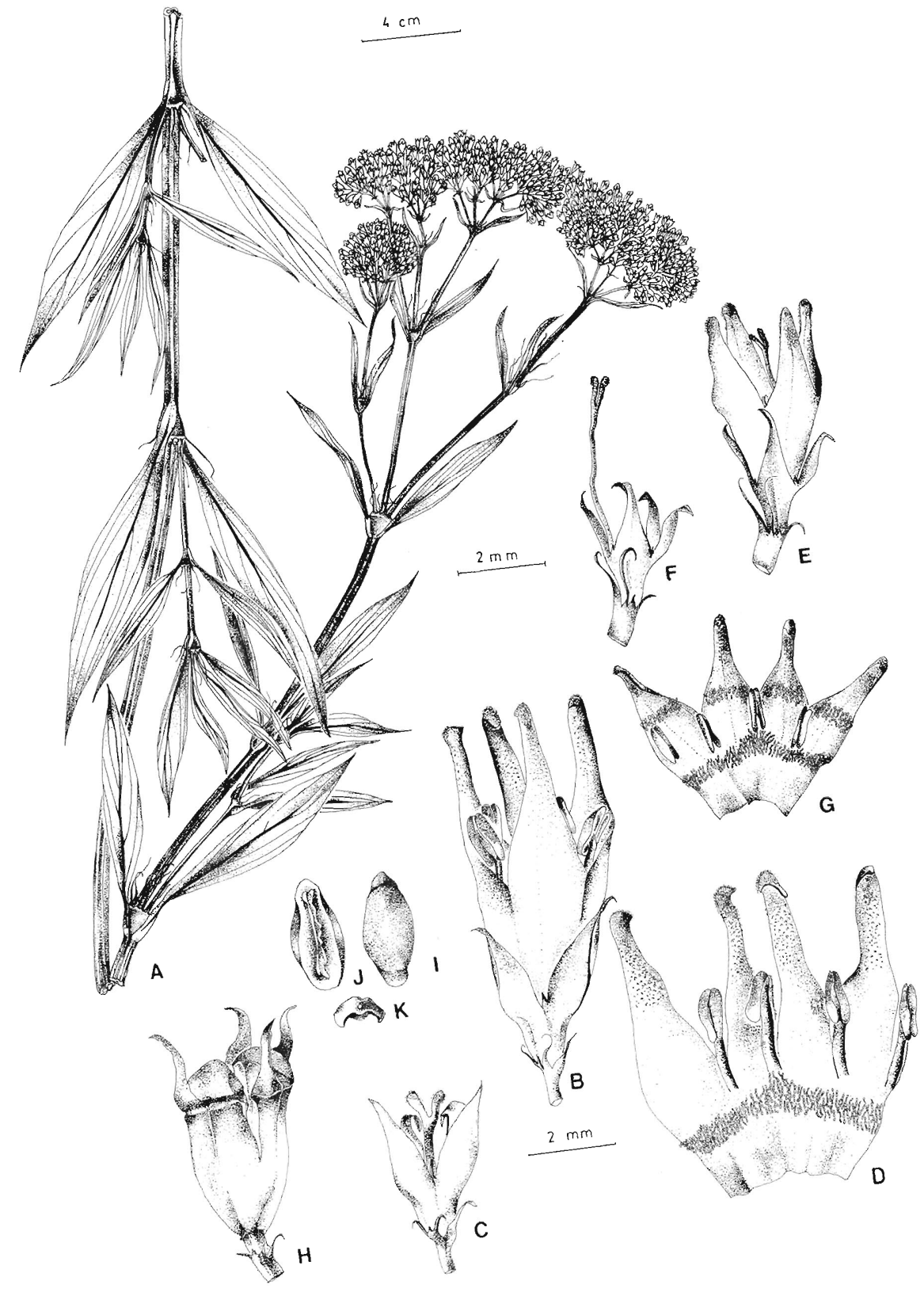


Sufrútice erecto, de 1-1,70 m, con xilopodio, tallo simple, subtetrágono, fistuloso, glabro, 3-8 mm lat., con entrenudos $1-15 \mathrm{~cm}$ long. Hojas coriáceas, lanceoladas u oblongo-lanceoladas, 30-130 × 2-15 mm, pseudopecioladas, base muy decurrente, ápice agudo a atenuado, haz glabro, envés con pelos cortos, antrorsos, sobre el margen y las venas; vena media y secundarias notables, 4-5 pares de venas secundarias subopuestas con ángulo de divergencia de $10^{\circ}$, impresas en el haz, resaltadas en el envés. Vaina estipular glabra a escábrida, 2-8 mm long., con 7-12 lacinias, filiformes, de 0,5-2,5 cm long. Tirsos amplios, corimbiformes. Cáliz de lóbulos triangular-subulados, 1,25-2,6 mm long., papilosos, con dientes interlobulares; hipantio turbinado, glabro, de 1-1,50 mm long., con rafidios dispersos. Corola blanca, con borde y dorso apical de los lóbulos papilosos; disco entero, papiloso. Flor brevistila: corola 3,30-6,50 mm long., con lóbulos más largos que el tubo corolino, superficie interna, con un anillo de pelos moniliformes sobre la mitad del tubo y papilas en la mitad superior de los lóbulos; filamentos estaminales gruesos, papilosos, 1-1,50 mm y anteras, 1-1,50 mm long.; estilo 2-3 mm long., grueso, bifurcado en su tercio superior. Flor longistila: corola 2-5 mm long., con lóbulos más cortos que el tubo corolino, superficie interna, con un anillo de pelos moniliformes delgados, en la mitad del tubo y pelos gruesos cortos, dispersos en la mitad inferior de los lóbulos, el resto papiloso; filamentos estaminales muy breves, anteras 1-1,25 mm long.; estilo 2-4 mm long., bifurcado en su quinto superior. Fruto glabro, turbinado, 2-4 mm long. Semilla 1,30-2,75 mm long., plano-convexa, con amplio surco alrededor del estrofíolo, con pequeñas alas apicales, escrobiculada.

Distribución geográfica: Vive en terrenos pantanosos o en borde de ríos y arroyos en Paraguay, en los departamentos Caaguazú y Amambay y en Brasil en los estados Mato Grosso do Sul, Paraná y São Paulo.

Paratipos. PARAGUAY. Caaguazú, Yhú, Jörgensen 4922 (SI); Amambay, Pedro Juan Caballero, 8.II.1951, Schwarz 11791 (CTES, LIL); Capubary, 14.III.1951, Schwarz 12129 (LIL). BRASIL. Mato Grosso do Sul, Maracajú, 29.XII.1973, Sucre 10523 (RB); Rio Brilhante, 25.I.1971, Hatschbach 26128 (CTES, MBM). Paraná, 
Curitiba, Bairro Alto, 31.XI.1973, Hatschbach 33914 (MBM). São Paulo, Campos do Jordán, IV.1945, Leite 3468 (LIL).

Obs. G. pseudopeciolata es afín a G. valerianoides (Cham. et Schldl.) Cabral, pero esta última especie tiene los tallos con pelos retrorsos en los ángulos, y hojas más anchas, de 130 a 230 mm lat., con la base obtusa o truncada.

\section{Agradecimientos}

Agradezco a los curadores de los herbarios consultados, al Ing. Carlos Zanín la corrección de las diagnosis latinas y a la Srta. Liliana Gómez por haber pasado a tinta los dibujos.

\section{Bibliografía}

Bacigalupo, N. M. 1974. Rubiaceae, en Burkart, A., Flora Ilustrada de Entre Ríos. Colec. Cient. INTA 6(6): 17-27.

Cabral, E. L. 1991. Rehabilitación del género Galianthe (Rubiaceae). Bol. Soc. Argent. Bot. 27(3-4): 235-249.

Candolle, A. P. de. 1830. Prodromus systematis naturalis regni vegetabilis 4: $540-551$.

Chamisso, L.A. et D. F. Schlechtendal. 1828. Rubiaceae. De plantis in expeditione speculatoria Romanzoffiana observatis rationem dicunt. Linnaea 3 (4):309-341.

Chodat, R. et E. Hassler. 1901. Plantae Hasslerianae II. Bull. Herb. Boissier, sér. 2, 4(2): 183-189.

Schumann, K. 1888. Rubiaceae, en Martius, C. Flora brasiliensis 6(6): 39-71.

Smith, L. B. 1958. Notes of South American phanerogams. J. Washington Acad. Sci. 48(9): 282-284.

- et R. Downs. 1956. Resumo preliminar das Rubiaceas de Santa Catarina. Sellowia 7: 17-86.

Standley, P. 1931. Studies of American Plants-V. Field Mus. Nat. Hist. Bot. 8(5): 392-395.

Steyermark, J. 1972. Borreria G. F. Meyer. The Botany of the Guayana Highland-part IX. Mem. New York Bot. Gard. 23: 805-831. 